\title{
RETRACTED ARTICLE: Cartesian vector-based directional nonparametric fuzzy filter for random-valued impulse noise removal
}

\author{
Ayyaz Hussain $^{1,2}$ • Muhammad Habib ${ }^{1}$ - Muhammad Ramzan ${ }^{2}$
}

Received: 14 July 2016 / Revised: 25 April 2017 / Accepted: 27 April 2017 / Published online: 9 May 2017

(C) Springer-Verlag London 2017

The authors have retracted this article because it has been previously published in Multimedia Tools and Applications [Hussain, A. \& Habib, M. (2017) A new cluster based adaptive fuzzy switching median filter for impulse noise removal Multimed Tools Appl DOI 10.1007/s11042-017-4757-z]. All authors have agreed to this retraction. The online version of this article contains the full text of the retracted article as electronic supplementary material.

Electronic supplementary material The online version of this article (doi:10.1007/s11760-017-1106-7) contains supplementary material, which is available to authorized users.

\footnotetext{
Ayyaz Hussain

ayyaz.hussain@iiu.edu.pk

Muhammad Habib

mhabibakhtar@gmail.com

Muhammad Ramzan

m.ramzan@seu.edu.sa

1 Department of Computer Science and Software Engineering, International Islamic University, Islamabad, Pakistan

2 College of Computing and Informatics, Saudi Electronic University, Riyadh, Kingdom of Saudi Arabia
} 